\title{
¿Un virus contra la identidad? \\ La construcción y mantenimiento de la identidad en personas, grupos y grupos sociales o sociedades, dañada.
}

\author{
J.M. Sunyer ${ }^{1}$ \\ Barcelona
}

\begin{abstract}
El 11 de marzo del 2020 la OMS declaró la pandemia por el Covid-19 a nivel mundial. Como consecuencia de esto, el 15 de este mismo mes el Gobierno de España estableció el estado de alerta, por el que los ciudadanos quedamos confinados en nuestros domicilios hasta nueva orden. En mi opinión esto afecta a la identidad de nuestra sociedad, a su identidad. En este texto me propongo explicártelo. Para ello analizaré la situación traumática, abordaré la cuestión de la identidad individual y social, desgranaré algunas de las consecuencias que se derivan y apuntando posibles salidas.
\end{abstract}

Palabras clave: Identidad individual y social, Pandemia Covid-19

On March the $11^{\text {th }}, 2020$, the WHO declared the pandemic due to Covid-19 worldwide. As a consequence of this, on the $15^{\text {th }}$ of this month the Government of Spain established a state of alert, whereby we citizens were confined in our homes until further orders. In my opinion this affects the identity of our society, its identity. In this text I intend to explain it to you. To do this, I will analyze the traumatic situation, I will address the question of individual and social identity, I will describe some of the consequences that follow and point out possible solutions.

Key Words: Social and Individual Identity, Covid-19 Pandemic English Title: A virus against identity? The construction and maintenance of identity in people, groups and social groups or societies, damaged.

\section{Cita bibliográfica / Reference citation:}

Sunyer, J.M. (2020). ¿Un virus contra la identidad? La construcción y mantenimiento de la identidad en personas, grupos y grupos sociales o sociedades, dañada. Clínica e Investigación Relacional, 14 (2): 469-492. [ISSN 1988-2939] [Recuperado de www.ceir.info ] DOI: 10.21110/19882939.2020.140217

\footnotetext{
${ }^{1}$ J.M. Sunyer, es doctor en Psicología, especialista en Clínica. Grupoanalista. Prof. Jubilado Facultad de Psicología de la Universidad Ramón Llull. Patrono de la Fundación OMIE. Director curso formativo en Psicoterapia Analítica Grupal en Madrid (U. Deusto- Fundación OMIE). Miembro fundador de la Asociación de Psicoterapia Analítica Grupal (APAG), Miembro del Instituto de Psicoanálisis Relacional (IPR). Miembro del Instituto de Grupoanálisis (Fund. OMIE). Miembro Honorario de la Group Analytic Society International (GASI) Dir. Contacto: josemiguelsunyer@gmail.com
} 


\section{Introducción}

Es posible que te sorprenda leer que la llegada a nuestro país del Covid-19 y el confinamiento al que nos hemos visto obligados, nos hayan sumergido en una situación traumática. Sería bueno verlo así: ha supuesto la paralización total de toda actividad económica y social. Por mucho que lo podamos entender, no deja de ser un mazazo para la mayoría de los ciudadanos.

Estamos ante una situación que afecta a toda nuestra estructura social: a los individuos y a sus familias, a los empleos, a las entidades económicas y financieras, a las estructuras sanitarias, educativas, etc. A toda nuestra sociedad. Implica a todos quienes la constituimos y en varios planos. En el vírico, no tanto por el número de personas diagnosticadas o por el de fallecidos, sino por la enorme presión que sostienen quienes les prestan ayuda, asistencia y sostén. El número de decesos — sobre todo gente mayorañade cierto pánico cuando alguien se nos acerca sin más.

También está afectando mucho a quienes tienen que vigilar por el mantenimiento del orden, del acatamiento de las normas para evitar contagios y, muy especialmente, a quienes deben velar por asegurar el abastecimiento de los ciudadanos y la conservación de las estructuras. El frenazo económico es evidente, como también el número de personas que se han apuntado a las listas del paro, los numerosísimos ERTEs que se han declarado, la paralización total del sector hotelero y de servicios, y toda la actividad académica y formativa. Se calcula que el PIB descenderá entre 6 y 9 puntos.

Algo muy oscuro nos ataca.

Además, la alarma generada y las lógicas medidas de confinamiento que tratan de contenerlo, han añadido más presión y angustia. Ya que, y aunque las cifras puedan no ser muy diferentes a las de otro tipo de enfermedades virales, su virulencia, capacidad reproductiva y de contagio han superado totalmente nuestras capacidades de contención, careciendo de un remedio que ataje drásticamente su progresión y desarrollo. A esto se le suma el complicado equilibrio entre informary alertar a los ciudadanos sin asustarles; sobre todo, cuando tras las tareas informativas también están los intereses por mantener e incluso incrementar las audiencias con las que se alimentan. En este sentido, es difícil mantener la mesura entre facilitar que los ciudadanos identifiquemos el peligro y colaboremos en contenerlo $y$, si fuese posible, erradicarlo, y activar identificaciones proyectivas en la población que, en vez de sembrar sosiego, acrecientan la ansiedad y los comportamientos incívicos. Siempre está la pregunta sobre si es buena o no la sobreinformación. 
Los profesionales -todos, desde el personal sanitario, a los servicios del orden, ejército y bomberos- que de forma tan ejemplar ponen todo su empeño por combatirlo, sufren las consecuencias de esa presión; con la angustia añadida de no contagiar a sus familias. Creo que bien podemos calificarla como de situación dramática global que afecta no solo a nuestro país sino a cientos. Esto, paradójicamente, es una ventaja; alivia la culpa de nuestros dirigentes políticos y nos coloca en un plano de igualdad relativa con otros países con los que nos comparamos permanentemente. En numerosas conversaciones con profesionales de la salud, esta situación es equiparable a la que se vivió en nuestro país por el $11 \mathrm{M}$, dándose desarrollos cercanos a la angustia (y hasta estrés) post-traumática que han requerido del apoyo profesional a muchos sanitarios y otros profesionales.

Desde un punto de vista grupal, si hacemos una lectura de las reacciones de la población y de los políticos que la conducen-, diría que ante la tensión que se vive aparecen claramente las tres reacciones que, en terminología bioniana (Bion, 1976) constituyen los supuestos básicos de «dependencia», «ataque - fuga» y «emparejamiento». La primera respuesta es la de muchos conciudadanos que aceptan sin más las órdenes emanadas desde el ejecutivo, considerándose bien gobernados y aceptando sin crítica alguna sus actuaciones. La segunda la adoptan muchos ciudadanos haciendo caso omiso de lo que se señala, obligando a tomar medidas de control de nuestros movimientos; de la misma forma que algunos dirigentes autonómicos buscan sembrar la duda y «arrimar el ascua a su sardina» pensando más en sus propios intereses (ideológicos y electorales) que en los de la ciudadanía. El tercer supuesto es el de emparejamiento, por el que la mayoría de los ciudadanos - y en especial los servicios sanitarios, así como los de protección civil, fuerzas del orden, bomberos y ejército- hacemos todo lo posible por colaborar, animar y apoyarnos para salir cuanto antes de esta durísima situación. La tensión entre estas tres posiciones se detecta fácilmente en las discusiones de nuestros representantes políticos, y en la prensa y medios de comunicación.

El ejecutivo, que es el conductor de ese grupo grande formado por todos, parece querer confirmar o reforzar la idea de emparejamiento ${ }^{2}$ a través de ofrecer abundante información. Digo «parece», porque no siempre proviene de una elaboración previa de lo que realmente está sucediendo, ofreciendo mensajes contradictorios y deslizando mucha de sus responsabilidades en los «expertos» o terceras personas. Alienta los aplausos a las 8 de la tarde en señal de apoyo y agradecimiento a quienes — sin apenas darles medios- se están dejando la piel atendiendo a los miles de personas contagiadas; a lo que se le añaden

\footnotetext{
¿¿Qué temerán? Porque no siempre la reiteración del mensaje sin explicar realmente a qué nos estamos enfrentando - que no es solo el virus, sino las consecuencias económicas que se derivarán — tranquiliza a un grupo grande que, por definición, está más próximo a las emociones que a la racionalización.
} 
un par de canciones que han servido como para aunar esfuerzos y mantener la moral: «Resistiré» y «Volveremos a brindar». Además, los constantes mensajes «de ésta saldremos», la información constante de las variaciones estadísticas de mortandad, altas, ingresos, etc., expresan tanto la preocupación por mantener el ánimo y no desfallecer, y la contraria: el miedo a que decaiga. Esto da la imagen de un ejecutivo desbordado.

\section{Situación traumática}

Entiendo por tal la exposición a una situación de estrés de naturaleza excepcional por la que el sujeto se siente amenazado u horrorizado por un peligro real, que aparece de forma casi repentina (aunque no siempre detectable), que altera total y drásticamente las pautas habituales de vida cotidiana. Como consecuencia, hay un profundo malestar, ansiedad y preocupación en muchísimas personas.

La RAE indica que un trauma es: a) el choque emocional que produce un daño duradero en el inconsciente; b) la emoción o i impresión negativa, fuerte

y duradera, y c) (y en medicina) una lesión duradera producida por un agente mecánico, generalmente externo. (Real Academia de la lengua española)

Tanto la primera definición como la que nos aporta la Academia de la Lengua, nos permiten aplicar la idea de situación traumática a la activada por el Covid-19 en nuestro país. Cualquiera de las tres acepciones sirve para definir lo que estamos viviendo estos días:

a) choque emocional, que se visualiza en el aumento exponencial de visitas a los centros asistenciales - no siempre suficientemente justificados-, junto al temor a ser infectado y las consecuencias en nuestros seres queridos alguno de los cuales, puede morir;

b) las emociones negativas, que se nos activan ante la incertidumbre, los bandazos gubernamentales e, incluso, ante la sobreinformación que genera efectos adversos, y cuya duración se prolongará durante meses; y

c) una lesión por un agente vírico, externo a nosotros, invisible que nos ataca a la mínima y sin poderlo detectar previamente.

Tomando las consideraciones psicológicas, la llegada de este virus nos ha colocado en una situación excepcional —confinamiento de la población — ante un peligro real —contraer el virus-, que perdura durante un tiempo realmente significativo - seis semanas, de momento-y que ha llevado a dictar una situación de alarma en todo el país. 
Calificarla como situación traumática puede ayudarnos a entender un poco más qué nos está pasando y pensar sobre ella. Con un pequeño agravante: como no es un agente concreto (como podría ser un ataque terrorista o una situación bélica) sino un virus al que no vemos, el miedo se acrecienta y perdura en el tiempo. No sabemos quién puede contagiarnos y quién no; incluso si nosotros mismos somos los portadores del virus. Hay un enemigo oculto, invisible, que se extiende con mucha facilidad del que tenemos que tomar precauciones; que activa recelos frente a cualquier persona que se nos acerque demasiado o ante una situación potencialmente peligrosa. Hay que extremar las medidas higiénicas, y proveerse de material — que no hay_para aminorar las posibilidades de contagio.

El causante es un «microorganismo compuesto de material genético protegido por un envoltorio proteico, que causa diversas enfermedades introduciéndose como parásito en una célula para reproducirse en ella.» (Wikipedia). Eso que es aparentemente manejable no lo es tanto e introduce una variable importantísima en lo que estamos abordando. Al no ser una cosa puntual sino como «terremoto inacabable» (Delás, 20203), la prolongación temporal va posponiendo la vuelta a la normalidad que se deteriora a diario. Lo que conlleva el desgaste de quienes luchan en primera línea de frente y el cansancio del resto de la población.

Para acabar de ponerle sal al asunto, hay una sobreinformación malévola por las redes sociales que facilitan la activación de pensamientos negativos, atribuyendo la existencia de ese ser microscópico a agentes extranjeros, a intereses ocultos, etc., que ponen en marcha ideas paranoides y catastrofistas. La insistencia en subrayar la carencia de material y de medios para hacer frente a la pandemia, en mostrar imágenes de escenas luctuosas e ideas contradictorias, incrementan, informando, la desinformación. Así como ver a un gobierno desbordado, indeciso, con medidas contradictorias y con tensiones evidentes en el ejecutivo. Por no añadir la cantidad de noticias falsas que introducen más confusión. ¿A quien creer? Esta situación nos afecta psicológicamente a todos nosotros, individual y colectivamente.

\section{¿A qué en concreto?}

Se ha producido una herida que tiene algo de narcisista; daña a la cotidianidad individual y colectiva, al mantenimiento de los hábitos cotidianos, a la convivencia -en muchas ocasiones en situaciones dramáticas- de muchísimas personas. No es un derrumbe total dado que hay una cierta esperanza de que los efectos no se extiendan por mucho tiempo;

3 J. Delás, 2020. Charla ofrecida por Convivencia Cívica Catalana en abril 2020 
pero sí conllevan un cuestionamiento de qué y quienes somos, qué hacemos y qué querríamos hacer; sobre todo a partir de ahora. Tal descalabro ha implicado y de forma diferente a quienes han tenido que bregar para paliar los efectos del virus sobre miles de ciudadanos, y a quienes, para no facilitar el contagio y contener la pandemia, nos hemos quedado en casa.

En el primer grupo incluyo a quienes trabajan en el mundo sanitario, a otros colectivos que prestan sus servicios a la colectividad como policías, bomberos, etc., y a quienes han tenido que supervisar el mantenimiento de los servicios mínimos de energía, alimentos, etc. Ahí, lo que se cuestiona no es su profesionalidad, sino la estructura sanitaria y su capacidad para hacer frente a situaciones catastróficas. En buena parte es la causante de que se hayan tenido que habilitar grupos de todo tipo para atender a los profesionales que, como poco, presentaban angustia por estrés post traumático.

En el segundo, a cada uno de nosotros: desde al ciudadano de a pie hasta a quienes forman el gobierno. Ahí el temor se sitúa no ya en el día después, sino que en muchísimos hogares no se sabe en qué medida va a cambiar su forma de vivir. Porque se desconocen cuán dañados están los diversos sectores que dan trabajo a la población; tanto en ciudades como en pueblos. Numerosos puestos laborales están amenazados. Se sabe que el número de personas en paro, con la destrucción de empleo y los ERTEs anunciados, alcanzan un número notable. Hay un derrumbe del sector servicios. Eso va a repercutir en las familias, en el mantenimiento de sus hogares - con las consecuentes tensiones en la convivencia. La industria se va a tener que reinventar y vamos a tener que producir internamente cosas que hasta ahora estaban deslocalizadas (lo que va a ser una ayuda).

Es posible que te sorprenda esta visión; pero creo que eso afecta a la identidad individual y colectiva. Quizás ayude ver qué se entiende por identidad y cómo ésta queda afectada.

\section{Identidad}

El concepto aparece de diversas formas en la literatura psicoanalítica. Freud lo menciona en Tótem y Tabú en cuanto a la identificación del sujeto con el Tótem, y también lo menciona en el Freud «Proyecto» vinculándolo con los avances de las neurociencias en su época, en concreto con la memoria. Grinberg $(1980,1993)$ también lo pone sobre el tapete. Y por supuesto Erikson (1971). Con todo, resulta arduo establecer una delimitación entre el de Self (sí mismo) y el de identidad, conceptos que, no siendo iguales, aparecen bastante imbricados entre sí (González, Fernández, Fernández, 2009). Ávila señala que «Los procesos identificatorios que configuran el narcisismo se tejen sobre las idealizaciones, que 
contienen una parte recibida por espejamiento y una parte proyectada desde el incipiente sentido de sí» (Ávila, 2014), lo que nos permite reafirmar que lo que podríamos llamar la construcción del sujeto está permanentemente vinculada a los demás. Eso nos confirma la idea de que la identidad no es un «objeto natural sino [una] elaboración social construida históricamente» (Páramo, 2008:540) como parte del proceso de nuestra civilización y cultura, y como resultante de los procesos de co-construcción que posibilitan nuestro desarrollo.

Considero que identidad es la experiencia que genera la vivencia personal de ser uno mismo a pesar de los cambios que se suceden en sus experiencias relacionales a lo largo del tiempo. Esta percepción -autopercepción si se quiere- debe ser el resultado de cinco tipos de vínculos complementarios:

a) los que el individuo ha establecido con las personas que han conformado, constituido y constituyen su matriz relacional;

b) con sus aspectos significativos con los que se identifica;

c) con objetos inanimados que adquieren un significado personal en base a su propia historia relacional con ellos;

d) con aquellos otros objetos internos interiorizados a partir de lo que su entorno le adscribe, y

e) de la elaboración de las experiencias a lo largo de su vida.

La identidad es esa imagen - y la conciencia que se deriva- que se construye a partir de sus relaciones de una persona consigo misma, y con todo lo que le rodea y constituye su existencia. Alude, pues, a aspectos de su self, su sí mismo, concebido como la imagen.

Posiblemente fuera Rousseau (1712-1778) quien habló primero de un periodo del desarrollo individual en el que el sujeto acaba definiendo su identidad. Concretamente fue en su cuarto libro de su «Emilio, o De la educación», cuando subrayó que entre los 12 y los 20 años se da una fase en el desarrollo individual a la que llamó adolescencia; un período del desarrollo sobre el que llueven abundantes instrucciones morales y educativas que le fuerzan a definir su propia posición.

"La adolescencia, según Rousseau, es una etapa particularmente sensible a los esquemas demasiado inflexibles. Es la única época en la vida que se caracteriza por una autosuficiencia de la «razón» y una actitud displicente ante la opinión. El adolescente tiende a ir más allá de sus necesidades elementales por lo que es necesario que distinga 
la utilidad real de las cosas para desarrollar la prudencia: la curiosidad bien dirigida es el móvil de la edad a la que hemos llegado» (Arrieta, J., 2002:151).

Es un período del desarrollo individual diferenciado en el que el sujeto se encontraría ante un debate: ¿qué priman más, mis razones, las de mi familia o las del entorno? ¿Cuáles son mis razones? ¿Cómo combino, o no, ambas fuentes de presión? Quizás el subrayado de Rousseau facilitó que se comenzara a prestar atención a lo que sucedía en este período y en nuestra cultura. Ello pudo despertar el interés en Stanley Hall por estudio de la adolescencia. En efecto, fue en 1904 cuando publicó su texto Adolescence, it's Psychology and it's relations to Physiology, Anthropology, Sociology, Sex, Crime, Religion and Education. En su planteamiento, el desarrollo individual sigue las pautas evolutivas de la humanidad - lo que recuerda a las etapas de las que Slavson hablaba en relación con la emergencia de la Psicoterapia de grupo, ¿verdad? -; pero, en cualquier caso, es a Erikson, a quien se le atribuye la paternidad del estudio sobre la identidad desde un punto de vista psicoanalítico (Erikson,1968,1956, Volkan, 2013, 2018).

En efecto, Erikson señaló que, durante el desarrollo, entre los 12 y los 21 años, se desarrollaba un $5^{\circ}$ período al que denominó «adolescencia y juventud (identidad vs difusión de la identidad)» (Erikson, E.H., 1972:2). Toda una etapa en cuyo centro encontrábamos la identidad y la confusión que se generaba. Ahí se daba un esfuerzo por armonizar o compatibilizar las identificaciones con los aspectos familiares que se habían dado durante la infancia y hasta el inicio de este período, y las que se van dando con los iguales y sus grupos de pertenencia.

Quien lo trasladó al ámbito social fue G. Mead, en 1934 cuando abordó este concepto, así como lo hiciera también E. Goffman (1980,1981). No entraré en el debate sobre la identidad, que es amplio. Sí quisiera subrayarte cómo en este trabajo ya resaltaba la importancia de los demás para uno mismo, definiendo el concepto de Selfy subrayando su aspecto social (Selves). En su opinión, la idea de sí-mismo aparece a partir del contacto con los demás, pudiendo diferenciarse de ellos y reconociéndoles en sus propios sí-mismos, sus propias identidades. Reconocer la identidad del otro conlleva la propia.

La identidad es esta sensación y conciencia individual que nace de las relaciones con los demás y de los que se diferencia. Se corresponde al desarrollo de la conciencia de la particularidad personal frente a la de los demás; y de que a pesar de los cambios físicos que se van dando, uno sigue siendo quien es. Se crea a través de la memoria narrativa de los hechos cotidianos, de las comparaciones entre narrativas, y de las elaboraciones de las experiencias compartidas. Ya que hay una continuidad entre lo que uno hace, lo que hizo y planea hacer; y al tiempo un contraste con las continuidades de los demás. Y que las 
variaciones que puede haber, como se dan de forma paulatina e integrada en el devenir diario, no generan un cambio brusco en el cómo se es.

Al derivarse de la narrativa que uno se hace de sí mismo y ante los demás, la mirada del otro tiene un papel importante en tanto que traslada una valoración u otra, una aceptación o lo contrario, una reafirmación en sus actuaciones y decisiones, o la crítica y consecuentemente desacreditación por parte del entorno. En realidad, ese otro no deja de significar el espejo en el que cada persona se ve reflejado, aceptado o rechazado. En último término esa metáfora alude a las experiencias que tiene todo ser desde el nacimiento, en su relación con la madre y otras figuras de relación y apego a lo largo de su infancia. Ahí juegan un rol importante las identificaciones con las figuras parentales y demás actores familiares con los que se relaciona.

Al llegar la adolescencia, período en el que el individuo se sumerge en relaciones grupales de diversa índole, va a tener que integrar formas de hacer que, en muchas ocasiones, rompen o se diferencian mucho de las familiares y habituales. Un conflicto entre espejos diversos. $Y$ en tanto que va pudiendo obtener el reconocimiento del entorno de los otros $y$ del familiar -lo que supone un intenso trabajo de elaboración interna-, la vivencia de continuidad persiste; evolución que integra el pasado y el presente, lo propio y lo ajeno. Cuando eso no se da, cuando hay rupturas, cambios significativos de toda índole, se crea el caldo de cultivo para la aparición de crisis de la identidad muy importantes.

\section{De la identidad individual a la colectiva}

Posiblemente no sea una novedad para ti: todo lo que hacemos implica al otro, somos más «homines aperti» que «homo clausus» (Elias, 1994, 2010). Individuos en constante interdependencia mediante la que nos hacemos y construimos a los demás. Permanentemente buscamos puntos de identificación con los demás y con las cosas que nos rodean. Mediante esta relación permanente y total con los demás, establecemos una continuidad entre nuestra identidad y la del contexto en el que nos encontramos; esto no significa que seamos iguales, sino que nuestra identidad está unida a una estructura identitaria más amplia que es en la que quedamos insertos y comprendidos. Un constante ejercicio de adecuación de las estructuras internas con las que nos rodean. Cuando eso no se da, la ruptura subsiguiente puede llevar a dificultades serias o a trastornos mentales significativos.

Eso permite entender algo de lo que sucede, por ejemplo, en los procesos migratorios: cuando se muda de lugar, con el tiempo el individuo se va mimetizando con el nuevo 
entorno, adoptando maneras, expresiones y hasta conductas más propias del lugar de acogida que del de procedencia. Cuando la emigración se produce de forma brusca, violenta, genera muchísimo dolor. Ahí, la activación de los elementos antigrupales (Nitsun, 1996) inherentes a toda inclusión forzada en un grupo y las pérdidas asociadas guardan mucha relación con las cosas que sostenían su identidad. La separación es también la de aquellos elementos que constituían esa continuidad de sí mismos; y del enorme esfuerzo que tienen que realizar por adoptar una nueva identidad. Eso en sí ya es traumático; pero más si sucede de forma brusca.

Somos seres relacionales desde nuestra concepción. Nuestros desarrollos -normo o patogénicos- son siempre el producto de nuestras relaciones con los demás, y la de ellos con nosotros. Nadie se hace a sí mismo. Todo lo que conlleva nuestro desarrollo implica siempre a los demás; y viceversa. Hasta el extremo que, si alguien naciera y no tuviera con quien relacionarse, aún siendo alimentado, no llegaría ni a pensar ni a hablar; de la misma forma que si quien emigra no se aclimata al lugar, acrecentará su nivel de sufrimiento ante la pérdida de los elementos que le sostenían en su identidad (Sunyer, 2011, 2012, 2013).

Cuando nos ponemos a estudiar al individuo podemos poner más acento en lo que sucede en su interior que lo que acontece en su relación con los demás. En principio incluimos en el primer grupo a los grandes psicoanalistas; pero en el segundo también hay referentes significativos. Y aunque es cierto que Freud se centraba en lo individual, ¿qué hacemos con su afirmación (tan manida) que indica que la psicología individual es, ante todo, psicología social? (Freud 1921). Ahí abre la puerta a una realidad sustentada por muchos de los situados en la órbita relacional y grupal. Desde este segundo lugar de observación tendremos que colegir que la identidad individual también será producto de esa relación con los demás.

¿Podríamos hablar de identidad colectiva? Si un grupo es el resultado de las relaciones que se dan entre quienes lo constituyen, su identidad derivará de las características que las definan: su historia compartida, sus particularidades respecto a otras identidades grupales de procedencia, de la memoria narrativa que se establece entre sus miembros, de las comparaciones con otras narrativas de grupos similares, y de la elaboración e integración de sus experiencias comunes. Cada individuo y las diversas constelaciones que se establezcan entre los componentes del grupo determinan esa identidad. Ahí, el juego figura vs. fondo (Lewin, 1965, 1988, 2012), es decir, primar la identidad individual o la colectiva, se coloca en primera instancia y no podemos separarnos de él. 


\section{¿Cómo se constituye el individuo?}

Todos tenemos —como organismo vivo—dos mecanismos básicos: percepción y memoria (Kernberg, 2009). Por el primero captamos instantáneamente todo lo que sucede a nuestro alrededor y en nuestro cuerpo. Mediante los sentidos, captamos las variaciones que se dan en nuestro derredor. Lo que nos permite tener la información necesaria para asegurar nuestra supervivencia. Por la memoria, registramos toda la información captada, permitiéndonos desarrollar planes de actuación para adecuarnos a los cambios que se dan en nuestro entorno y en nuestro propio cuerpo. Esto es biología pura (Siegel, 2007); y por lo tanto también psicología.

Un bebé no tiene otra cosa que hacer que registrar todo lo que le sucede e integrarlo. Sus redes neuronales captan todo lo que pasa a su alrededor y en sí mismo, estableciendo circuitos cuyo uso activarán la memoria de eso que captó. A más uso, más fijación. Así, la presencia reiterada de su madre, el sonido de su voz, la forma de cogerlo, tocarlo, mecerlo, etc., queda registrado de forma que cada nuevo encuentro reactiva esos circuitos $y$, reforzándolos, los memoriza y le permiten adquirir un conocimiento de su madre. Lo mismo le sucede a ella. Esta «capacidad de memorizar la experiencia posibilita el apego hacia los demás» (Siegel, 2007:63) y también su inserción en la matriz grupal -y social-a la que pertenecemos (Foulkes, 1957, 2005). Al retener toda esa información, tomamos nota de sus características. Nuestro desarrollo armónico precisará de este ligamen con los demás para constituirnos como sujetos insertos en la matriz relacional familiar y social.

A los primeros procesos de captación de toda esta información les llamamos introyecciones (Laplanche; Pontalis, 1981, Freud, 1982, Kernberg, 1988). Mediante esa operación mental —fundamentada en la neurología (Siegel, 2007:60) — hacemos nuestros los aspectos de nuestra relación con el entorno, constituyéndose así los rudimentos de lo que más adelante denominaremos nuestro Yo. Pero al tiempo, desechamos aquellas percepciones que nos sobrepasan por su exceso de intensidad (no por su valoración cualitativa ${ }^{4}$. Al proceso por el que expulsamos aquellas percepciones que nos resultan insoportables le llamamos proyección.

Proyectamos, pues, aquellos aspectos que superan nuestra capacidad adaptativa. Al hacerlo quedan «depositados» en — sería como atribuidos a -las personas o lugares de los que creemos que proceden. Introyección y proyección son los dos mecanismos iniciales de todo ser mediante los que comienza su construcción y la de su entorno. Perviven toda la

\footnotetext{
4 Una intensidad excesiva asusta y se rechaza porque se percibe peligrosa. expresa. Este material es para uso científico y profesional exclusivamente y puede contener información clínica sensible. Los editores no se responsabilizan de los contenidos de los autores. Dirigir las consultas sobre derechos y autorizaciones a ceir@psicoterapiarelacional.es
} 
vida y se activan de forma especial cuando se dan situaciones que superan nuestra capacidad de actuar, provocando regresiones psíquicas.

Así, construimos nuestro Yo, a los demás y a nuestro entorno. Cuando el bebé capta la voz de su madre, el tono cómo le habla, la intencionalidad que transmite, su ritmo y cadencia, etc., lo interioriza, grabándolo en su memoria y organizando el reservorio de información con la que se construye: él va siendo esa información. Mediante esta relación privilegiada, se modela a su imagen, asemejándosele a los aspectos que son su alimento psíquico. Cuando por alguna razón hay un sonido brusco, o un cambio en su forma de hablar que le asustan —sobresaltan-, tiende a proyectarlo —desecharlo-, no haciéndoselo inicialmente propio (esto requiere un tiempo de maduración que por lo general no se adquiere hasta los ocho o diez meses, Kernberg, 1988). Queda, eso sí, el registro de algo que sucedió y le angustió (Siegel, 2007). Los relatos de estas experiencias emocionales también intervienen en el proceso de creación de la identidad, personal y colectiva.

Cuando la maduración de las estructuras neuronales lo permiten, se alcanza otro grado en el que toda esta información adquiere un valor significativo mayor, denominándoselas identificaciones. Ahí lo que capta tiene ya una estructura formada por, al menos, tres componentes que forman una unidad psíquica: la percepción del objeto ${ }^{5}$, la tonalidad afectiva con la que se le asocia, y la imagen —relacional del ligamen ${ }^{6}$ - que se establece entre el sujeto y el objeto (Kernberg, 1988). Esto es muy elemental en sus inicios; pero la progresiva maduración de nuestro cerebro posibilita la organización de la información de sus relaciones con el mundo; lo que también se traduce por un incremento del número de sinapsis. De ahí que podamos decir que somos el producto de las interacciones con las personas con las que nos relacionamos, identificándonos con aspectos suyos y con los derivados de esa relación vincular. $Y$ cuando las personas de referencia afectiva básica presentan variaciones en sus comportamientos de apego (Bowlby, 1998), nuestra identidad también las presentará: en tanto que interioriza (y memoriza) los estilos relacionales que se establecen con ellas.

La estabilidad de estos vínculos facilita la construcción de la identidad individual y relacional: el bebé «sabe» con qué se va a encontrar, qué estímulos va a recibir y cómo son estos estímulos. Por esto, cuando hay algún estímulo novedoso, la primera reacción es de sorpresa. Al constatar que encaja con el resto, se lo integra como parte de su identidad relacional. Esto es un proceso activo que dura toda la vida. Ahí se van asentando las bases

\footnotetext{
${ }^{5}$ La idea de objeto alude a todo lo que no corresponde al sujeto. Todo lo que él percibe, sea del entorno o de sí mismo, es considerado como tal.

${ }^{6}$ El entre rayas es un añadido mío. El confinamiento me alejó de mi biblioteca.
} 
de su identidad individual y, en tanto que está inmerso en unas relaciones, va captando elementos que tienen que ver con su identidad social. Las dos identidades se constituyen mutuamente, la individual y la social.

Pero no solo nos hacemos, sino que también construimos nuestro entorno: las personas que nos rodean y con las que establecemos vínculos afectivos están hechas, desde nuestra percepción, a imagen de lo que les atribuimos. Así, al tiempo que el bebé se construye, forma también a «su madre», y a los que vayan apareciendo a su alrededor. El mundo y quienes nos rodean son el resultado de lo que somos capaces de percibir y de lo que les atribuimos. A más información —esto es, más relación- más nos acercamos a la realidad que nos rodea. El otro y lo que nos rodea, siempre es producto de nuestra subjetividad; que es una característica activa en tanto que proviene de nuestras atribuciones. $Y$ al serlo, nos mueve a actuar y reaccionar a partir de lo que significa para cada uno lo que percibe y la forma cómo lo hace. Eso nos conduce a un constante modelado de la realidad y del otro, para ajustarlo a lo que nos interesa, importa y deseamos desde nuestra propia percepción y experiencia.

De esta manera construimos a los demás. Mediante nuestras acciones y reacciones, presionamos, a quienes nos atienden y rodean, a ser y a mostrarse de una manera $u$ otra en base a nuestros esquemas internos. Nuestros mecanismos de poder están activos desde los primeros compases de nuestra vida extrauterina una vez que, transcurrido el parto, se nos diluyen las «identificaciones primarias con la madre7» (T.Burrow, citado por Campos, J. 2020, y por Pertegato; Orge Pertegato, 2013). Ya en el mundo real, modelamos nuestro entorno a nuestro deseo -es decir, a las personas que lo constituyen-; al tiempo que somos modelado por quienes nos rodean. Se establecen así las bases de nuestras interdependencias. Lo que proyectamos sobre nuestro entorno, lo que introyectamos de él, los elementos con los que nos identificamos, disociamos o negamos, lo que presionamos mediante las identificaciones proyectivas o somos modelados por las introyectivas, todos nuestros mecanismos de defensa y comunicación están al servicio de la construcción personal y la del entorno.

Se da, pues, una doble construcción que forma una unidad. De un parte, construimos el mundo y a quienes lo constituyen desde nuestra propia subjetividad. De otra, influimos y lo modelamos en base a nuestras propias necesidades y deseos, ejerciendo un poder sobre ellos y sus formas de actuar que busca modular sus respuestas, sus propuestas y sus relaciones con nosotros. A la capacidad relacional que el individuo posee de generar

\footnotetext{
7 Burrow sostuvo ante Freud su teoría sobre la identificación primaria con la madre, un concepto que indica el vínculo con ella antes del parto, por lo que es una vivencia pre-consciente, esto es, anterior a la consciencia.
} 
cambios en el otro -en su forma de pensar, obrar, etc. - le llamamos poder (Elias 201; Castells 2016). Éste no es un componente personal. No es un atributo individual. Es un determinante relacional, inserto en toda relación con el otro y la de ese otro para con uno. Es una característica relacional. (Elias, 2011, Castells, 2016).

Los vínculos que establecemos con las personas que nos rodean y su estabilidad configuran las vivencias de continuidad de nuestra existencia y la del entorno en el que nos desarrollamos. La estabilidad vinculante contribuye a la interiorización de esas experiencias. El entorno ejerce también su correspondiente influencia — ¿presión? - sobre el neonato y posterior niño y adulto. En este interjuego de influencias recíprocas y en su continuidad se edifican las bases de la identidad individual, familiar y social. En ello intervienen activamente nuestros mecanismos de comunicación y defensa en ambos planos, el inconsciente y el consciente. En el primero, tratando de ajustar las vivencias relacionales (con sujetos y objetos) de forma que el nivel de ansiedad permanezca en niveles tolerables. En el consciente, comunicándonos —en armonía con los mecanismos de defensa- con el objetivo de ajustar la experiencia relacional y vinculante a nuestras necesidades. A partir de ahí, la forma cómo vamos conteniendo las diversas experiencias relacionales con el entorno determinarán los estilos de relación y nuestra conciencia de identidad.

\section{La intencionalidad constructiva}

Como quiera que nuestra identidad se construye mediante la variedad de elementos de identificación con los demás, con nuestro entorno, con sus formas de pensar, de hacer, etc., igual te estarás preguntando sobre qué grado de intencionalidad hay en ello, ¿verdad?

La mayor parte de nuestras identificaciones se producen involuntaria e inconscientemente; y las que no nos lo parecen, también tienen elementos inconscientes que las sustentan. En algunas, media la voluntad propia o un cierto grado de conciencia y deseo — ser como él, en otras, la presión del entorno. Así, cuando los padres señalan que «nosotros lo hacemos de esta forma» o aluden a historias familiares, proezas, anécdotas, etc., no dejan de mostrar elementos con los que, más allá de dar información «de la familia», ofrecen datos con los que nos podemos identificar. En ocasiones media el orgullo de esa pertenencia, en otros el diferenciarnos de otras familias. O de otras clases sociales o ideologías. El mismo nombre o apellido -incluso su orden cuando éste es decidido por los padres- viene cargado de las identificaciones que pueden proceder de uno mismo o del que los 
progenitores le ponen, trasladando esa información, de forma sutil, a quien lo lleva. Nunca es banal el nombre que ponemos a nuestros hijos. Tampoco la forma cómo lo vivimos.

Pero también hay que considerar cómo contribuye el entorno social a la construcción de la identidad. No me refiero solo al que circunda a la familia, sino cómo las diversas figuraciones sociales ${ }^{8}$ (Elias, 2011) coparticipan en el establecimiento de una identidad compartida. En efecto, los centros educativos son la primera prueba que todo niño debe afrontar y en el que experimentará su propia conciencia social. Desde la guardería hasta la universidad el individuo establece lazos mediante los que crea identificaciones con personas, objetos y símbolos. Cualquier centro educativo transmite una serie de informaciones y patrones de comportamiento que pasan a ser componentes de la identidad de sus alumnos ${ }^{9}$. Igualmente, los centros deportivos, culturales, religiosos, etc... Las instituciones educativas, sociales, deportivas y de tiempo libre o trabajo, también aportan información acerca de qué aspectos les caracterizan por el hecho de pertenecer a ellos — sea de índole religiosa, cultural, social, étnica o política-. Toda la experiencia compartida, los ideales y las metas a las que se aspira, son utilizadas como elementos sobre los que depositamos cargas y significados personales con los que nos sentimos vinculados a la institución formando parte de la identidad personal de cada miembro.

Igualmente, la cultura que se labra en cada lugar se expresa mediante mensajes, canciones, relatos, juegos o actividades que se enseñan por doquier: en casa, en el colegio, en los centros culturales etc., pero también los medios de comunicación ${ }^{10}$ transmiten mensajes acerca de la identidad colectiva. Cuando quien emite la información no la ha procesado personalmente, fácilmente puede inocular en el mensaje vivencias que están más ligadas con identificaciones proyectivas o introyectivas.

Las vías por las que el sujeto capta información útil para la construcción de esa identidad son múltiples. En las familias, se introducen, voluntariamente o no, detalles que caracterizan su identidad y que van ligadas con las experiencias personales de los mayores. Mayormente, son aspectos sutiles, informaciones que vienen al paso de cualquier momento y que las hacemos nuestras porque pertenecemos a ese grupo. En otras, son vivencias que captamos al percibir el sufrimiento o el placer asociado a determinadas

\footnotetext{
${ }^{8}$ Para Elias, una figuración es cualquier organización social al servicio de algo. La familia, el colegio, el club deportivo, el gobierno, etc., son figuraciones sociales.

9 Antes que se escribía y se hacía caligrafía más que ahora, diferenciábamos quienes iban a un colegio o a otro por la caligrafía. Ahora será por otras cosas.

${ }^{10}$ En muchas ocasiones, la información viene sesgada por la de quienes gestionan los medios de comunicación o sus presentadores. También la publicidad ejerce un papel importante en este juego. En realidad, estamos inmersos en redes de comunicación que determinan qué información se transmite, cómo y cuando con la finalidad, declarada o no, de generar un tipo de identidad colectiva.
} expresa. Este material es para uso científico y profesional exclusivamente y puede contener información clínica sensible. Los editores no se responsabilizan de los contenidos de los autores. Dirigir las consultas sobre derechos y autorizaciones a ceir@psicoterapiarelacional.es 
experiencias, o anécdotas del pasado de nuestros mayores. Por ejemplo, podemos identificarnos con el orgullo de nuestro padre cuando habla de determinadas historias. $O$ con el de nuestra madre, cuando destila algunas emociones relativas a cuando era joven. Por lo general son relatos que están también muy vinculados con su propia historia y, en consecuencia, cargados de identificaciones de cualquier signo.

También aparecen otros modelos de identificación: personajes revolucionarios, cantantes, líderes políticos o con capacidad mediática, personajillos a través de las redes sociales... Porque más allá de las influencias familiares también hay que considerar otras muchas. Muchas veces, la propia vestimenta denota afinidades con ideologías, movimientos religiosos o políticos; o desea transmitir una determinada imagen que capte las posibilidades de que quienes nos vean se asemejen a nosotros. Casi toda la publicidad se basa en ello; incluso la dirigida a los niños. No es raro ver a figuras mediáticas anunciando determinados productos. ¿Por qué? Por los elementos de identificación que subyacen en ellos.

En este orden de cosas, el oficio que tenemos, nuestro trabajo, la familia y el hogar (y el lugar) en el que vivimos, el resultado económico de nuestro esfuerzo laboral, el desarrollo de nuestros hijos, el bienestar de nuestros allegados y amigos, etc., también forma parte de nuestra identidad. Incluso nuestros hábitos diarios, el café de todos los días, esa cerveza con personas a las que apreciamos y sentimos su aprecio. O la sonrisa de los hijos -e incluso sus rabietas cuando las hay-, las preocupaciones cotidianas, etc., por mucho que sorprenda también forman parte de nuestra identidad.

\section{Objetos y dianas de identificación}

En el desarrollo normal de toda persona se da un fenómeno curioso, aunque altamente significativo: la elección de objetos que no solo recuerdan un hecho en nuestras vidas, sino que quedan empapados de cargas afectivas vinculadas al hecho que se recuerda. Y acaban constituyéndose como partes de nuestra identidad. Sobre ellos proyectamos vivencias que sobrepasan nuestra capacidad de contención y, al ubicarlos fuera, nos permiten vivir sabiendo que ahí hay huellas de nuestra identidad. En ocasiones hay trazos de identificación proyectiva en ellos; en otros, de la introyectiva.

Todos guardamos una multiplicidad de cosas, de objetos varios: postales, cartas de personas queridas, retratos, e incluso trastos absurdos que para nosotros tienen un significado personal: esa estatuilla horrorosa (a ojos de otro) pero que representa un fragmento, un detalle de nuestra historia. Pensemos en las herencias. ¿Acaso no se dan 
situaciones en las que tener un detalle de nuestros padres generan alta tensión entre los hermanos? ¿Qué valor tendrá aquella cinta métrica que perteneció a un tío abuelo al que a penas conocí? ¿Valor económico? Ninguno. Ni como antigualla. Pero el valor que tiene para $\mathrm{mi}$, hace que sufra por si se rompe o extravía. Son a modo de aquellos objetos sin los que no podíamos dormir; objetos transicionales (Winnicott, 1971) entre nuestra realidad cotidiana y un hecho, situación o persona del pasado. ¿Los miramos todos los días? No. Ocasionalmente los vemos, ahí están. ¡Malo será el momento en el que no los encontremos!

¿Por qué sucede eso? Te comenté que uno de los mecanismos que utilizábamos en la construcción de nuestra identidad era la proyección. Expulsábamos de nuestra consciencia aspectos que por su intensidad o significación nos resultaban excesivos. Cierto. Hay cosas en las que depositamos — proyectamos_un significado personal por el que esa cosa deja de ser un objeto vulgar y queda convertido en algo significativo. La razón proviene de la carga afectiva y simbólica que le ponemos - ya que dejarla meramente en la memoria no es factible por la intensidad que tiene- ¿Acaso no tienes un cajón, un lugar en el que guardas una serie de porquerías sin importancia alguna, pero que nunca tiras? Porque cuando decides hacer limpieza, llegas, miras y... lo dejas como está. ¿Será porque el valor afectivo, simbólico que ahí reposa es importante para ti? Pues eso, las personas adjudicamos unas cargas afectivas, simbólicas, a objetos a cosas. Al hacerlo, dejan de ser cosas banales; ya tienen valor. Da igual que sea una servilleta de papel, una piedra o un dibujo.

Ahora bien, cuando desaparecen o se dañan algunos de estos objetos o situaciones cuya carga afectiva depositada es de mucha intensidad, nuestras reacciones pueden estar fuera de nuestro control. La vivencia excede la capacidad de control emocional, lo que nos indica que no es una mera proyección: es una identificación proyectiva. Porque al identificarnos así en ese objeto o situación, su daño o desaparición es nuestro propio daño o la desaparición de un fragmento de Yo depositado ahí. Se da en algunas rupturas matrimoniales o, la de las relaciones con la persona amada en la adolescencia. El daño que eso genera afecta al Yo. No es un mero rasguño, es la identidad de uno la que ha quedado maltrecha.

En otras ocasiones, cuando alguien nos atribuye una característica que para nosotros es intolerable - por la identificación introyectiva con ella-, nuestra reacción es también muy violenta: la vivimos como un ataque personal, una pedrada en nuestra identidad que hasta aquel momento estaba inmaculada. Por poner un ejemplo, cuando le decimos a un ser querido algo así como «eres un desastre» - por decir algo suave-, si el valor que tiene 
«desastre» es muy importante -identificación introyectiva-, la reacción suele ser desproporcionada a la intención de quien lo dijo.

Fíjate en la de situaciones que se dan. Guardamos aquella servilleta de papel en la que aquella chica nos puso su nombre cuando teníamos i14 añosi; el palo de hockey —roto yacon el que marcaste aquel gol; esta estilográfica de tu primera comunión que no sirve y está con la plumilla rota. $Y$ podríamos hacer un listado muy largo. Pero también, cuando nos vamos a vivir una temporada larga a otro lugar, entre nuestros enseres hay alguna cosa que está ahí por el valor simbólico que tiene para nosotros. Los emigrantes traen consigo objetos que no tienen en sí mismos ningún valor; pero sí lo tienen para ellos. Están cargados de simbolismo. $Y$ destruirlos supondría una pérdida irreparable para ellos. Cuando emigramos a otro lugar, ¿por qué tratamos que nuestro nuevo hogar nos recuerde al que tuvimos? Porque eso nos hace sentir que mantenemos nuestra identidad individual, conservando un vínculo con lo que dejamos. O tuvimos que dejar. En el fondo, actuamos como el niño que se va a dormir con su osito de peluche (recuerdo de su madre de la que se separa): tomamos algo que nos acompaña en nuestros cambios de vivienda y que simboliza - por la carga afectiva depositada - los lazos con el pasado, con lo que dejamos y su pervivencia en nuestra identidad.

Pues bien, eso que nos sucede individualmente, también se da en las familias, en los grupos y las sociedades. Objetos, fechas, relatos que, al estar cargados de significados importantes, acaban teniendo un valor sagrado o casi. Ya que les colocamos algo de nuestra identidad; la individual y la colectiva.

De forma muy similar sucede en el terreno social. Todos los grupos humanos -las sociedades entre ellos - poseen esos recuerdos que mantienen viva la idea de identidad colectiva. Los hay de todo tipo: monumentos a plazas, edificios, árboles, piedras, colinas, montañas, etc. Unos, aluden a momentos del desarrollo histórico de nuestro país (La Alhambra, la muralla de Ávila, las joyas mudéjares), otros a emblemas religiosos (Catedral de Santiago, la de Burgos, la Sagrada Familia, etc.); también muchísimos nombres de nuestras calles o plazas -o incluso el mantenimiento de lugares tristemente famosos durante la pasada guerra civil-, o estatuas (Monumento a Colón en Barcelona, al general Prim, a los caídos en Filipinas, etc.). ¿Qué sentido tienen todos ellos? Mantener algo del recuerdo de la historia colectiva que, de la misma forma con la que guardamos el palo de hockey, forman parte de nuestra identidad.

Nos lo explica bien Volkan (1997, 2018): sirven para externalizar vivencias que por su intensidad o por el valor que le adjudicamos, tienen un significado que, sin ser de nadie, son de todos. Representan ese sentimiento de seguir siendo lo que fuimos (en ocasiones, lo que 
se pudo ser). Su valor no tiene por qué ser el del objeto en sí sino el que se le adjudica. En este sentido, la única diferencia entre esa pluma rota que guardas en tu cajón y el arco de la victoria de Mérida está en que el primero alude a la identidad personal mientras que la otra es la colectiva.

\section{Daños de esa identidad}

Desde bien pequeño sabes que dañas más a cualquiera de tus hermanos estropeándoles algo que es suyo (la muñeca, esa construcción que está haciendo, etc.) que dándoles un tortazo. El daño, siendo aparentemente menos agresivo, es más dañino. Y nadie te lo enseñó. Intuías, como todos, que ese juguete era parte de su identidad -aunque no le pusieras ese nombre-, que, rompiéndoselo, manchándoselo, le provocabas mucho dolor. ¿Verdad? Entonces tu instinto, tus averiguaciones científicas infantiles te informaban que la identidad deriva y está conectada con el conjunto de aspectos con los que nos hemos identificado individual o colectivamente: cosas que son importantes para nosotros. $Y$ que, al sostenerse sobre objetos (materiales o no) que la simbolizan, los daños provendrán de las agresiones que sufran unos $\mathrm{u}$ otros.

Pues bien, eso no solo nos ocurre a las personas sino a sus diferentes agrupamientos: familias, colectivos y sociedades. Cualquiera que sea el número de personas e independientemente del tipo de figuración o constelación (Elias, 2010, Sunyer, 2011) que organicen, acaban teniendo objetos, fechas, celebraciones, lugares etc., cargados de las proyecciones que individual y colectivamente se depositan en ellos. Su daño, su deterioro o pérdida va más allá de su materialidad — que en último término podría ser restablecidaya que su valor deriva de la significación afectiva y simbólica atribuida por las personas a las que, también, une. Los procesos de identificación de los que habló Freud (1921) van más allá del hecho de depositar en una o unas figuras aspectos del ideal de cada individuo: se colocan sobre objetos, fechas, lugares, etc., que quedan cargados de los elementos de la identidad personal y colectiva depositados en ellos.

Los daños a la identidad pueden provenir de dos fuentes: de la mano del hombre o de la naturaleza (Volkan, 1997, 2013, 2018). Dependiendo de su procedencia, la reacción es diferente. Los primeros son, como cuando éramos pequeños, aquellos que provienen de la acción (voluntaria o no) de un igual, de otra persona. Este es el caso de las peleas entre hermanos, amigos, compañeros de trabajo, vecinos o, y de forma mucho más drástica, de otro grupo o sociedad (país). Sus consecuencias son desastrosas; a las que se le añade la ira que nos destroza, la vergüenza por la humillación y las ganas de venganza. Que, por lo general y fundamentalmente cuando afecta a más de una persona, se transmiten —en 
ocasiones con cierto deseo perverso- de generación en generación (Volkan,1997, 2013, 2018). Su reparación solo es posible cuando entramos en procesos individuales y colectivos de perdón y olvido (Sunyer, 2020). La reparación solo pasa por ahí.

Los otros daños, los derivados de la naturaleza tienen otra resolución. Fundamentalmente porque no podemos achacarlo a un tercero. Aceptamos que la naturaleza es más fuerte que todos nosotros. ¿Qué hacer frente a un terremoto, una inundación, el desborde de unos ríos, la subida extraordinaria de la marea, los huracanes, el fuego o la caída de un rayo, etc.? Nada. Paliar sus daños. Rehacer nuestras vidas. Y asumir nuestra pequeñez -lo que no es poco- Ciertamente, en estos casos como en los generados por la mano del hombre, la identidad individual y colectiva ha quedado dañada. Pero en esta segunda situación aceptamos que la naturaleza no ha ido contra nosotros, y que su fuerza es infinitamente superior a la nuestra. Podemos, sí, maldecir al destino, a Dios o a cualquier ente superior. Pero nada más.

\section{¿Y el Covid-19?}

Es un virus, lo que lo vincula a la naturaleza. Y casi mejor lo dejamos así. Al atribuirlo a algo de esta procedencia, ¿qué podemos hacer sino combatirlo, crear los recursos sanitarios para ello y comenzar a pensar en sus próximas ediciones o las de sus parientes cercanos? Y tratar de reconstruir la identidad perdida.

Veamos el recuento de daños. Porque son profundos. Quizás uno de ellos pueda ser la pérdida de la confianza en nosotros mismos, en lo que habíamos construido. Creíamos disponer de un sistema de vida que tenía las garantías suficientes como para no temer algo así. Como si un planteamiento tan basado en la voracidad del individuo -en otros términos, diríamos codicia-, esa búsqueda en tener más que el vecino se nos viniera abajo. Como en el cuento de los tres cerditos, nos pensábamos que aquella casa de paja era suficiente. ¿Con qué contábamos?

a) Estábamos muy lejos del peligro. A pesar de las múltiples señales de su realidad y acercamiento progresivo, no le dábamos crédito. Creíamos que ni iba a llegar a Europa y mucho menos a nuestro país. Utilizamos la negación como mecanismo de comunicación y defensa.

b) Pensamos que disponer de los mejores profesionales de la medicina -lo cual no hay duda, por su valía personal y bien hacer profesional- nos bastaba; aunque no les dimos elementos para hacer frente a una enfermedad. La soberbia nos 
traicionó, considerándonos por encima del bien y del mal. Ahí perdimos el contacto con la realidad, como si fuese «su problema» cuando era el de todos.

c) No valoramos la fragilidad de un sistema económico y productivo excesivamente pendiente de terceros. Pero no por las personas que lo sostienen sino por que su estructura era débil, carente de la elasticidad y fortaleza que debería haber tenido. Todo lo construido, todo lo que con el sudor de trabajadores y empresarios se nos vino abajo. En este punto, nuestra identidad como sociedad equiparable a otros países del entorno, se nos vino abajo. La idealización de nuestra estructura se rompió en mil pedazos. Así como negar que estamos en un mundo real, en el que hay una competición por dominar al otro.

d) También nuestro sistema educativo se fragmentó. El curso escolar y académico iniciado hace unos meses quedó descuartizado. Es cierto que los esfuerzos de muchos profesionales de la enseñanza han tratado de evitar el desplome total; pero las heridas son patentes. Posiblemente eso haya servido para que algunos se den cuenta del valor de los profesionales de la educación, de lo complejo y difícil que es trabajar con niños y no tan niños. Hay que reconstruir un sistema educativo -a todos los niveles- que valore a sus profesionales y a la educación en sí. De poco sirve devaluar su importancia.

e) Pérdida de la credibilidad en nuestros dirigentes. Independientemente del color que posean, la imagen que han transmitido y transmiten - todos, insisto- es de desnorte, de improvisación, de caciquismo y amiguismo, y de falsedad informativa. Ver cómo en base a determinadas comisiones se priman compras o no. Genera frustración que importe más no perder la imagen ideológica que proporcionar seguridad y tranquilidad al grupo humano que conducen. Y más con el uso torticero de los datos. La negación como mecanismo de defensa y comunicación. La devaluación del oponente, del otro. Lo personal se coloca por encima de los social.

f) Pero, y lo más flagrante, es que muchas familias se van a ver ante la tesitura de abandonar su hogar o con la dificultad de recuperar un trabajo que permitían una economía, exigua, pero que les era útil, así como el mantenimiento de una identidad labrada a base de dolor, sudor y esfuerzo. La despersonalización como recurso grave de supervivencia. Ya no son personas, son solo votantes.

Esto se nos ha venido abajo por un enemigo invisible que ha sido capaz de arruinar nuestra economía familiar y colectiva. El dolor que sentimos proviene del derrumbe de aquellos valores y características que mal que bien nos habían permitido una vida relativamente cómoda para muy buena parte de la población. Ahora todo esto amenaza ruina, o está en 
entredicho. Y nos aboca a realizar un profundo duelo no siempre fácil de sostenerlo sin levantar ese dedo acusatorio. Decía García Badaracco que cuando señalamos con el índice no vemos a los otros tres dedos acusándonos a nosotros mismos. No será fácil elaborar que son cinco los dedos que apuntan en direcciones diferentes.

Se nos presentan momentos de desfalcos, rupturas de la convivencia familiar y social, y otras circunstancias económicas que vendrán acompañadas por grietas en nuestra identidad individual y colectiva. Y que igual que con la herida por la muerte de personas significativas — un hijo, un hermano, la pareja que también forman parte de la identidad de uno-, deberemos afrontar el duelo para suturar la herida generada. Y ante ello, una amenaza compleja: el uso perverso de los elementos identitarios: ser de tal bando o de cual región, de tal categoría o de cual estatus, de tal partido o de cual equipo deportivo. Los elementos de esta índole son tantos que fácilmente encontraremos las fórmulas para no hacer una autocrítica seria y serena.

\section{¿Qué hacer ante eso?}

Difícil dar una respuesta global. El hombre no es un ser carente de maldad. Busca su propio interés - por mucho que lo vistamos de otra cosa —, ansía disponer de mayor poder sobre el otro. Pero el poder, la base de nuestras relaciones, no pertenece a nadie, surge de la propia relación. Y ¿en qué consiste? En la capacidad de modelar la mente del otro mediante la palabra (Elias, 1994, 1999, Castells, 2009) y, cuando ésta no lo consigue, mediante la acción y fuerza. Modelar la mente del otro es algo que hacemos todos. La cuestión es ¿qué intencionalidad hay detrás de esa forma de poder?

En la medida que los representantes políticos, los profesionales y los ciudadanos tengamos más formación, más educación, y aprendamos a utilizar nuestras capacidades en beneficio de todo, iremos bien. De lo contrario, lo tenemos complicado. Crear una nueva sociedad no es algo que se haga en un abrir y cerrar de ojos. Supone edificar una nueva conciencia sobre nuestra propia naturaleza que tenga presente nuestra capacidad destructiva para contrarrestarla por la capacidad creativa. Esto es la potenciación de los trabajos en colaboración con el otro, y la emergencia de una filosofía del vivir que pueda compatibilizar el desarrollo de las personas con el mantenimiento de nuestra tierra, nuestro hogar.

Lamentablemente si esto se consiguiera, tendríamos que decir ¡Bienvenido Covid-19! 


\section{REFERENCIAS}

Arrieta, J. (2002). Propuesta desde un encuentro de ideas pedagógicas: Rousseau y Freire. Revista Educación 26 (2), 147-158.

Ávila, A. (2014). Intersubjetividad y soluciones narcisistas. Del Narcisismo proactivo fuente de soluciones protésicas para la identidad a sus transformaciones. Temas de psicoanálisis. 8, 112

Bion. W. R. (1976). Experiencias en grupo, Buenos Aires: Piados.

Bowlby, J. (1998). El Apego. Barcelona: Paidós

Campos, J. Trigant Burrow, el pionero en grupoanálisis. http://arxius.grupdanalisi.org/GDAP/JCA_Burrow_M.pdf (Recuperado el 20 de marzo 2020)

Castells, M. (2009). Comunicación y poder. Madrid: Biblioteca Nueva

Diccionario de la Lengua Española. Real Academia de la Lengua https://dle.rae.es/trauma?m=30_2. (Recuperado el 8 de marzo de 2020)

Elias, N. (1994). The Civilizing Process, Oxford, Blackwell, Hay versión española: (1987). El proceso de la civilización, Madrid, Fondo de Cultura Económica.

Elias, N. (2010). Sociología fundamental. Barcelona: Gedisa

Erikson, E. (1956). The problem of ego identity. Journal of American Psychoanalitic Association 1, 56-121

Erikson, E.H. (1968). Identity: Youth and Crisis. NY: Norton.

Erikson, E.H. (1972). Sociedad y adolescencia. México: Siglo XXI

Foulkes, S. H., Anthony, E. J., (1964), Psicoterapia psicoanalítica de grupo, Buenos Aires, Paidós

Foulkes. S.H.; Anthony, E. J. (1957), Group Psychotherapy. The Psycho-Analytic Approach, Great Britain. Pinguin Books. Hay versión castellana actual en (2007), Psicoterapia de grupo. El enfoque psicoanalítico. Barcelona. Cegaop press

Foulkes, S.H. (2005). Introducción a la psicoterapia grupoanalítica, [1948] Barcelona: Cegaop press.

Freud, A. (1982). El yo y los mecanismos de defensa, Barcelona, Paidós.

Freud, S. (1968). Proyecto de una Psicología para Neurólogos. Obras Completas, T III. Madrid: Biblioteca Nueva

Freud, S.H. (1968). Psicología de las masas y análisis del Yo. Obras Completas. Vol. IV Madrid: Biblioteca Nueva.

Gatti Pertegato, E.; Pertegato, G. O. (2013). From Psychoanalysis to Group Analysis. The pioneering work of Trigant Burrow. London: Karnac

Goffman, E. (1980). La representación de la persona en la vida cotidiana. Buenos Aires: Amorrortu 
Goffman, E. (1981). Estigma, la identidad deteriorada. Buenos Aires: Amorrortu

González, M.A.; Fernández, A.; Fernández, E. (2009). Identidad, relación y construcción del selfen el encuentro psicoterapéutico. Revista de la Asociación Española de Neuropsiquiatría. 27(1) 77-84. Recuperado en 11 de abril de 2020, de http://scielo.isciii.es/scielo.php?script=sci_arttext\&pid=So211$57352007000100006 \&$ Ing=es\&tlng=en.

Grinberg L., Grinberg R. (1980). Identidad y Cambio. Barcelona: Paidós.

Kernberg, O. (2005). La teoría de las relaciones objetales y el psicoanálisis clínico. México: Paidós Laplanche, J.; Pontalis, J.B., (1981). Diccionario de psicoanálisis, Barcelona: Labor.

Lewin, K. (1988). Teoría del campo social. Barcelona: Paidós

Lewin, K. (2012). Dinámica de la personalidad. Selección de artículos. Madrid: Morata

Lewin, K., y otros. (1965). El niño y su ambiente. Argentina. Paidós

Mead, G. (1934). Mind, Self and Society. Chicago: U. C. Press

Nitsun, M. (1996). The antigroup. Londres: Routledge

Páramo, P. (2008). La construcción psicosocial de la identidad y del self. Revista Latinoamericana de psicología 40 (3), 539-50

Rouseau, J. (2011). Emilio, o De la educación. Alianza Editorial,

Siegel, D.J. (2007). La mente en desarrollo. Bilbao: Desclée de Brouwer

Sunyer, J.M. (2011). Vínculos, alianzas e interdependencias. En J.M. Sunyer (2018) Escritos grupoanalíticos. Toda una vida aprendiendo. Madrid: viveLibro

Sunyer, J.M. (2012). La mente no es individual. En J.M. Sunyer (2018) Escritos grupoanalíticos. Toda una vida aprendiendo. Madrid: viveLibro

Sunyer, J.M. (2013). El proceso de individuación. En J.M. Sunyer (2018) Escritos grupoanalíticos. Toda una vida aprendiendo. Madrid: viveLibro

Volkan, V. (1997). Blood Lines: From Ethnic Pride to Ethnic Terrorism

Volkan, V. (2013). Psicología de las sociedades en conflicto. Barcelona: Iniciativas grupales

Volkan, V. (2018). Psicología de las sociedades en conflicto. Barcelona: Herder

Wikipedia: virus. https://es.wikipedia.org/wiki/Virus (Recuperado el 12 de abril de 2020)

Winnicott, D.W. (1971). Realidad y juego. Barcelona: Gedisa

Original recibido con fecha: $13 / 4 / 2020 \quad$ Revisado: 16/4/2020 Aceptado: 30/09/2020 